\title{
El coronavirus. ¿Estábamos preparados?
}

\author{
The coronavirus. Were we prepared?
}

\author{
Luis Octavio Sánchez-Vargas,* Amaury Pozos-Guillén*
}

\section{RESUMEN}

El planteamiento de este artículo no es presentar la gravedad del problema a nivel local, nacional y mundial, tampoco hacer un análisis científico, técnico, económico o social de toda la información publicada recientemente respecto a la enfermedad COVID-19 y sus consecuencias. El objetivo principal es reflexionar sobre tres preguntas que impactan a nuestra comunidad de profesionistas de la odontología, instituciones de educación encargadas de la preparación de futuros profesionistas e investigadores: 1. ¿Qué aspectos positivos existen derivados de esta pandemia que debemos rescatar y qué no estamos viendo? 2. ¿Qué podemos aportar desde una perspectiva profesional y social durante esta emergencia de salud pública? 3. ¿Qué cambios positivos se habrán generado en nuestra profesión cuando esta pandemia sea controlada?

Palabras clave: Coronavirus, COVID-19, odontología.

\section{ABSTRACT}

The approach of this article is not to present the seriousness of the local, national and world problem, neither to give a scientific, technical, economic or social analysis of all the recently published information regarding the COVID-19 and its consequences. The main objective is to reflect on three questions that impact our community of dentistry professionals, educational institutions responsible of preparing future professionals and researchers: 1 . What positive aspects are derived from this pandemic that we must rescue and that we are not seeing?; 2. What can we contribute from a professional and social perspective during this public health emergency ?; 3. What positive changes will have been generated in our profession when this pandemic is controlled?

Keywords: Coronavirus, COVID-19, dentistry.

\section{INTRODUCCIÓN}

$\mathrm{E}$ n diciembre de 2019 se presentó un tipo de neumonía emergente en la ciudad de Wuhan, provincia de Hubei en China; el 30 de enero de 2020 la Organización Mundial de la Salud declaró una emergencia internacional debido a esta enfermedad y al virus que la causa, la enfermedad respiratoria se ha designado como COVID-19 y el virus causante ha sido nombrado inicialmente como 2019-nCoV y renombrado el 11 de febrero como SARSCoV-2 basados en su filogenia y taxonomía.

Este coronavirus, ya con una propagación mundial para el día 14 de abril del año en curso y a reserva de la posible subestimación, ha infectado a prácticamente dos millones de personas, causando la muerte de más de 125 mil seres humanos (aproximadamente el 6\%)

\footnotetext{
* Facultad de Estomatología, Universidad Autónoma de San Luis Potosí. San Luis Potosí, S.L.P., México

Recibido: 14 Abril 2020.

Aceptado para publicación: 18 Abril 2020.
}

en el mundo debido al progreso de la neumonía y a sus complicaciones. Italia, España y recientemente Estados Unidos han sido los países con un mayor número de casos y muertes asociadas.

Los estudios han demostrado que los virus respiratorios pueden ser transmitidos de persona a persona de manera directa (contacto con mucosa oral, nasal, y ocular) o indirecta (tos, estornudos e inhalación de gotas de saliva). Un informe de un caso de infección por SARS-CoV-2 en Alemania indica que la transmisión del virus puede ocurrir a través del contacto con pacientes asintomáticos, ya que el virus puede estar en el aire a través de aerosoles (como los formados durante procedimientos médicos).

Esta emergencia sanitaria ha puesto a prueba los sistemas de salud a nivel mundial, que sobra decir son de muy diferente índole, y poco a poco ha ganado la batalla, poniendo en riesgo la salud de una gran cantidad de personas. Las medidas sanitarias para tratar de controlar esta pandemia tomadas desde la aparición del primer caso han sido diversas, algunas de ellas discutidas y muy seguramente no adoptadas al $100 \%$ por la población, por diferentes razones. Lo anterior, como profesionales 
de la salud, nos obliga a reflexionar sobre la aparición de situaciones médicas de esta naturaleza y sus implicaciones en la vida diaria y en el contexto de salud donde ocurren. Definitivamente, $y$ a pesar de las medidas tomadas y de los esfuerzos para concientizar a la población sobre las consecuencias médicas de la infección, el panorama parece oscuro y grave.

Quizás para muchos profesionales de la salud odontológica la pregunta gira en torno a si deberíamos salir corriendo a comprar cubrebocas, mascarillas, caretas, guantes y toda clase de barreras de protección certificadas y soluciones desinfectantes hasta llenar nuestra reserva para los 10 años siguientes. La realidad es que no. Si bien sin menoscabo de las comunicaciones oficiales, los métodos y recomendaciones de un buen control de infecciones tienen un carácter indiscutible y establecido desde hace mucho tiempo y con carácter de «universalidad»; es decir, que nuestras conductas de protección son aplicables en todo momento y circunstancia durante la atención a nuestros pacientes. Debe quedar claro que los diversos procedimientos clínicos que se realizan en un consultorio dental implican cierto riesgo, pero esta definición no es a partir de la pandemia de COVID-19. La atención a los pacientes no es ni debe ser selectiva, por ello debemos utilizar siempre y en todos los casos nuestras barreras de protección de manera eficiente, así como la desinfección de superficies entre cada paciente y una evaluación inicial minuciosa de todos nuestros pacientes como parte básica de cada consulta, independientemente del tratamiento a realizar. Es cierto también que situaciones de esta naturaleza han sido clave para tomar conciencia e implementar medidas de bioseguridad para la prevención y control de infecciones cruzadas; como ejemplo de ello, recordemos que hace algunas décadas la infección por VIH tuvo muy buena aplicación preventiva en los consultorios odontológicos, y más recientemente con el brote de influenza en el año 2009.

SARS-CoV-2 ingresa a las células humanas siguiendo la misma ruta que el coronavirus del SARS, la enzima convertidora de angiotensina II (ACE2 por sus siglas en inglés) es el receptor celular de éstos. Las moléculas ACE2 se expresan en el tracto respiratorio y en la cavidad oral y están altamente expresadas en células epiteliales, siendo mayor su expresión en la lengua que en los tejidos bucales y gingivales. Estos hallazgos indican que la mucosa de la cavidad oral puede ser una potencial ruta de alto riesgo de infección por SARS-CoV-2.

Los pacientes y profesionales odontológicos estamos expuestos a microorganismos patógenos, incluidos virus, hongos y bacterias que infectan la cavidad oral y el tracto respiratorio. Los entornos de atención dental invariablemente conllevan el riesgo de infección por SARS-CoV-2 debido a procedimientos de rutina, que implican la atención cara a cara con los pacientes y la exposición frecuente a saliva, sangre y otros fluidos corporales, así como el manejo de instrumentos punzocortantes.

Como integrantes de una comunidad y ante la pandemia incontrolada, debemos acatar y «no atacar» las recomendaciones de nuestros sistemas de salud; como profesionales de la salud odontológica debemos apegarnos siempre a un estricto control de las infecciones, incluidas las emergentes. Por otro lado, a pesar de que en los próximos meses se controle la pandemia desde un punto de vista de la salud pública, el SAR-COV-2 es un patógeno emergente que seguirá circulando por un largo periodo, desconocemos cuánto tiempo pasará hasta tenerse lista una vacuna eficaz, tratamientos antivirales y, en su caso (si ocurriera), la erradicación del virus. La realidad es que este virus pasa a formar parte de los patógenos de alto riesgo en tanto siga circulando, así que la enseñanza deberá revisar y reafirmar nuestros procesos, entrenar a los futuros profesionales en un apego estricto a las medidas universales de control de infecciones y que éstas formen parte estricta de los objetivos profesionales.

Hoy ha quedado al descubierto una realidad respecto a la bioseguridad ocupacional. Como profesión deberemos eliminar las conductas de riesgo; en principio por seguridad propia, y no menos importante, por la seguridad para que los pacientes no se infecten de algún patógeno durante su consulta o tratamiento odontológico. Además, deberemos hacer énfasis por mantener una conducta ética y no hacer caso omiso de que hoy esta pandemia nos está mostrando las debilidades que existen en los procesos, y el riesgo latente al que estamos expuestos y al que podríamos exponer a nuestros pacientes cuando se omiten principios universales de bioseguridad. En este sentido, y para entender la importancia de lo anterior, el SARS-COV-2 tiene un número reproductivo básico (R0) de 2.5 a 5 , es decir, que cada infectado puede trasmitir el virus a dos y hasta cinco personas más. No obstante, otros virus tienen un índice R0 similar o mayor, como el caso del virus del sarampión que tiene un índice R0 de 12 a 18, o el virus de la varicela que tiene un R0 de 10 a 12; inclusive existen bacterias como la Bordetella pertussis que causa la tosferina con índices superiores de contagiosidad. Como podemos advertir, el riesgo de adquirir o trasmitir un patógeno durante los procedimientos odontológicos no es nuevo, y la sola existencia de extensos consentimientos informados que incluyen a toda la lista de patógenos de riesgo no son suficientes para deslindar responsabilidades con los pacientes. Es imperativo apelar a nuestro mayor sentido ético para enfrentar esta emergencia sanitaria. 
Como profesionales de la salud oral, ¿qué deberíamos hacer ante una emergencia de este tipo? Varias posibilidades se nos vienen a la mente; una de ellas, que es la que la inmensa mayoría ha adoptado, son las dificultades e implicaciones de todo tipo como «cerrar el consultorio e irnos casa», mientras que otros profesionistas trabajan desde casa. Si bien, no es posible hacer una extracción dental, una cavidad o una preparación dental para una prótesis de manera virtual, la pregunta es iqué sí es posible hacer desde nuestra casa o consultorio sin que el paciente tenga que acudir? ihay varias respuestas y propuestas! A reserva de otras que todos podamos aportar:

Educación para la salud oral. Hay una lista inmensa de situaciones que podemos atender desde esta perspectiva de la educación para la salud; hoy la gente está en casa y es de esperar que algunos hábitos cambiaron por esta simple realidad y ¿en cuánto estará aumentando su consumo de alimentos ricos en carbohidratos? ¿Sus hábitos de higiene bucal serán los correctos? En este sentido, quizás podríamos hacer una serie de recomendaciones para que la gente cuide su alimentación mientras estamos en esta etapa de la contingencia, circulemos una lista de alimentos deseables en una dieta para prevenir las enfermedades bucales, sobre todo de aquellos alimentos que la gente debería evitar consumir en exceso. Sin duda alguna, y en sinergia con expertos de otras profesiones, podemos ayudar a nuestros pacientes desde nuestra propia casa y con acciones «simples». Gastemos nuestros esfuerzos y «nuestros datos» en compartir y circular la información, enviemos imágenes, presentaciones, documentos, videos, audios, tutoriales y todo tipo de apoyos de las correctas técnicas de higiene oral incluido el cepillado dental, el uso de hilo dental, de enjuagues antisépticos e insistir en el lavado de manos. Recordemos que hoy muchos niños estarán en casa junto con sus padres, quizás es la oportunidad de que éstos puedan vigilar el cepillado de sus hijos como hace mucho no ocurre. Hoy «sí tenemos tiempo».

Consultas virtuales. Otra posibilidad que tenemos hoy y apoyados de la tecnología es la de brindar asesorías a nuestros pacientes, donde podamos resolver dudas, identificar los casos donde será necesario atender físicamente al paciente en un corto tiempo o darle una serie de recomendaciones para poder frenar el avance de lesiones o enfermedades orales, y que alguna de éstas no lo lleve al hospital durante la contingencia. Podemos tener un día y horario específico para atender esas emergencias que hayamos detectado durante las «videoconsultas», trabajemos con responsabilidad y hagamos las menores salidas posibles, esto lo podemos prevenir mediante las consultas virtuales. No obstante, la Organización Mundial de la Salud (OMS) recomienda que, en este momento, no deberemos atender a un paciente en el consultorio si éste se encuentra con la enfermedad, y si se trata de una emergencia deberemos seguir las recomendaciones emitidas por la Asociación Dental Americana. De paso, cabe decir que esta pandemia nos ha mostrado el valor intangible del uso de las tecnologías, así que los modelos próximos deberán incluir cada vez más el uso de estas herramientas para la práctica de nuestra profesión.

Educación continua. En la actualidad a nadie le resulta raro escuchar una videoconferencia, un «webinar» o incluso un tutorial o una clase más desarrollada. La profesión y enseñanza odontológica debe adaptarse a esta nueva realidad sin menoscabo de la enseñanza presencial. Estamos ya en esta realidad de educación y preparación.

Esquemas de vacunación. Hoy tenemos claro el valor de las vacunas, desearíamos en este momento recibir la noticia de que esté lista una vacuna efectiva contra el SARSCOV-2, incluso los gobiernos están haciendo esfuerzos por apoyar los protocolos de investigación existentes; sin embargo, ¿qué porcentaje de los profesionistas odontológicos tienen un esquema de vacunación incompleto respecto a las vacunas ya existentes? Es momento de reflexionar y actuar al respecto, revisemos la cartilla de vacunación y hagamos conciencia del valor que tienen en nuestra propia salud; pongamos en marcha un plan, para que en breve esté completado y establezcamos una estrategia para revisar los esquemas de nuestros pacientes y para promover que todos cuenten con las vacunas completas.

¿Qué otros cambios se están produciendo durante esta crisis de salud? Desde el ámbito odontológico, en la formación de profesionales de la salud y como parte de la responsabilidad académica, estamos encargados de impulsar cambios y actualizaciones curriculares, quizás el más importante es la revisión y adecuación de los programas de las asignaturas que conforman un plan de estudios, enfatizando en los siguientes temas como dimensiones transversales a lo largo de la formación:

- Prevención y salud pública.

- Métodos de control de infecciones.

- Aprendizaje en línea y uso de las tecnologías durante la práctica.

- Desarrollo ético la profesión.

- Importancia de la normativa y situaciones emergentes.

- Resiliencia ante las crisis y una posición de liderazgo como servidores de la salud.

- Uso correcto de fuentes de información. 
- Aprendizaje desde la perspectiva de odontología basada en la evidencia.

Estos son sólo algunos aspectos a manera de resumen ante la situación que vivimos. Es necesario también hacer un análisis reflexivo desde nuestra posición, ya sea como docentes, investigadores, directivos, profesionistas o estudiantes. ¿Cuál ha sido nuestra visión, cuál nuestro aprendizaje y cuál será la visión que deberemos adquirir después de superar la emergencia? La crisis pasará y la recordaremos por siempre, pero la oportunidad de lograr el mayor aprovechamiento de lo aprendido quedará para los siguientes meses o años, o mejor aún, se reflejará en nuestro actuar como clínicos en beneficio de nuestros pacientes, quienes no merecen menos.

En este momento, nos hemos hecho la pregunta ¿cuándo, pero sobre todo, cómo volveremos a nuestra actividad cotidiana? En este sentido, vale la pena establecer un plan de acción para nuestra inminente reincorporación a la práctica clínica. Como ejemplos, algunos de nosotros estamos dedicando este tiempo de crisis a revisar los procesos clínicos, a escribir o actualizar los manuales operativos incluyendo detalladamente las conductas a seguir para nuestra seguridad en todo lo que respecta al control de infecciones; otros estamos revisando nuestras finanzas y replanteando la planeación estratégica financiera formulada hace tiempo y que ahora debe contemplar este aprendizaje para tomar en consideración emergencias y crisis. Después de esto «no seremos los mismos».

Son muchas las reflexiones, son muchas las inquietudes, son muchas las perspectivas, pero sobre todo, son muchas las oportunidades. La invitación es que juntos podamos establecer aquéllas que suman a nuestra vida, a la sociedad y al mundo, y que esta nueva oportunidad que nos brinda la vida se conduzca desde el optimismo y desde los valores que hayamos aprendido, después de la pandemia por COVID-19 la realidad en el mundo definitivamente será otra. La odontología no está lejos de esa realidad, será parte de la cotidianeidad y de las necesidades de la gente como lo ha sido siempre, pero seguramente los profesionistas verán a cada paciente con un símbolo de riesgo y probablemente el paciente hará lo mismo cuando acuda a una consulta dental. ¿Estamos preparados?

\section{LECTURAS RECOMENDADAS}

1. Xu H, Zhong L, Deng J, Peng J, Dan H, Zeng X et al. High expression of ACE2 receptor of 2019-nCoV on the epithelial cells of oral mucosa. Int J Oral Sci. 2020; 12 (1): 8.

2. Chen J. Pathogenicity and transmissibility of 2019-nCoV-A quick overview and comparison with other emerging viruses. Microbes Infect. 2020; 22 (2): 69-71.

3. Ather A, Patel B, Ruparel NB, Diogenes A, Hargreaves KM. Coronavirus disease 19 (COVID-19): implications for clinical dental care. J Endod. 2020. pii: S0099-2399(20)30159-X.

4. Peng X, Xu X, Li Y, Cheng L, Zhou X, Ren B. Transmission routes of 2019-nCoV and controls in dental practice. Int J Oral Sci. 2020; $12(1): 9$.

5. Spagnuolo G, De Vito D, Rengo S, Tatullo M. COVID-19 outbreak: an overview on dentistry. Int J Environ Res Public Health. 2020; 17 (6): E2094.

6. Meng L, Hua F, Bian Z. Coronavirus disease 2019 (COVID-19): emerging and future challenges for dental and oral medicine. J Dent Res. 2020; 99 (5): 481-487.

7. Berlin-Broner Y, Levin L. Dental hierarchy of needs' in the COVID-19 era - or why treat when it doesn't hurt? Oral Health Prev Dent. 2020; 18 (2): 95.

8. ADA Interim Guidance for Minimizing Risk of COVID-19 Transmission. Disponible en: https://success.ada.org/en/ practice-management/patients/infectious-diseases-2019-novelcoronavirus

Correspondencia:

Amaury Pozos-Guillén
Facultad de Estomatología,
Universidad Autónoma de San Luis Potosí.
Av. Manuel Nava 2, Zona Universitaria,
78290, San Luis Potosí, S.L.P., México.
E-mail: apozos@uaslp.mx

Amaury Pozos-Guillén

Facultad de Estomatología

Universidad Autónoma de San Luis Potosí.

78290, San Luis Potosí, S.L.P., México.

E-mail:apozos@uaslp.mx 